\title{
PROPAGATION OF DRY HABITAT FERN SPECIES USING SPORE COLLECTIONS FROM HISTORIC HERBARIUM SPECIMENS
}

\author{
Gunnar $\emptyset v$ steb $\phi^{1}$, Alex Twyford ${ }^{2} \&$ Tina Westerlund ${ }^{3}$
}

\begin{abstract}
Spores sourced from historic herbarium specimens have been used to introduce wild-collected material to the Royal Botanic Garden Edinburgh (RBGE) living plant collection. The ability of dry habitat ferns to maintain spore viability for prolonged periods makes it possible to grow plants from the historically important RBGE herbarium collections. The factors that affect the ability of spores to germinate from herbarium collections are described. Three fern species from the Pteridaceae - Actiniopteris semiflabellata, Anogramma leptophylla and Aleuritopteris scioana which were not previously in cultivation at RBGE were germinated from herbarium material of different ages. Germination was observed from all three species. Plants produced in this experiment were accessed into the RBGE living plant collection for future horticultural research and germination trials.
\end{abstract}

\section{INTRODUCTION}

Ferns (Pteridophytes) are a diverse and species-rich group, with some 12,000 species distributed across all continents except Antarctica. These species are adapted to a wide range of habitats, from wet tropical areas to seasonally dry and dry areas. Many of these species are poorly represented in cultivation, particularly species that have evolved in an environment which is dry for much of the year.

Ferns germinate from spores and these give rise to a gametophyte plant which is haploid (Ranker et al., 2008). This early establishment stage can be precarious in natural environments and its success is dependent on the environmental and edaphic conditions where the spore lands. Fern spores are tiny, being of a similar size to a pollen grain, $<0.01 \mathrm{mg}$ (Mehltreter et al., 2010), and have very few resources within them to support growth. In natural conditions, spores may survive in the soil spore bank and will subsequently germinate when suitable conditions occur. The lifespan of a spore in the soil spore bank can be as little as two days and as long as forty years - in the green spore group and non-chlorophyllous spore group respectively (Dyer, 1979). Therefore spores of groups with longevity in natural environments are excellent candidates for testing the viability of spores from dried samples. For species that are now rare or extinct in the wild, archived dried samples in the herbarium may be the only source of plant material.

1. Gunnar $\emptyset_{\mathrm{vsteb} \emptyset}$ is a horticulturist in the Indoor Living Collection at the Royal Botanic Garden Edinburgh, specialising in the cultivation of arid plants. Address: 20A Inverleith Row, Edinburgh, EH3 5LR. Email: G.Ovstebo@rbge.org.uk

2. Alex Twyford is a PhD student in molecular plant sciences at the University of Edinburgh and the Royal Botanic Garden Edinburgh.

3. Tina Westerlund is a horticulturist and $\mathrm{PhD}$ student in heritage conservation at the University of Gothenburg. 
The propagation of ferns using spores from herbarium collections has previously been tested, with reports of viability ranging from a couple of days to a few decades when kept at room temperature. Fernandez et al. (2010) suggest that spore viability of dry adapted fern species can be maintained for 10-15 years when stored at room temperature. This is consistent with data from other spore germination experiments (Pray, 1968; Windham et al., 1986). The oldest known spores to germinate from herbarium material are from Marsilea quadrifolia, which germinated 100 years after it was collected (Johnson, 1985). This may be due to the spores being enclosed in a protective sporocarp which resists desiccation.

The primary aim of this study was to germinate fern spores from herbarium specimens in order to enrich the Royal Botanic Garden Edinburgh (RBGE) Living Collection with species that are not currently cultivated. A particular emphasis was placed on dry adapted ferns from the Arabian Peninsula, which are poorly represented in cultivation. The implications of the success of this study will also be explored and recommendations will be made on which spores should be collected from herbarium specimens for cultivation in the future.

\section{MATERIALS AND METHODS}

\section{Selection of specimens}

The Herbarium at RBGE holds a comprehensive collection of fern species from the Arabian Peninsula. The earliest collections are from an expedition to Soqotra led by Isaac Bayley Balfour in 1880. Since then a number of expeditions have made collections and since 1977 more intensive fieldwork has taken place in connection with RBGE's Flora of Arabia project. Three species from the Arabian Peninsula with multiple collections held in the Herbarium were selected as described below. The presence of duplicate specimens of each species allows the germination success of spores to be compared between replicate herbarium sheets. Full specimen collection details are available in the RBGE online herbarium database (RBGE, 2010).

\section{Actiniopteris semiflabellata Pic. Serm.}

This is a small fern, green in the wet season and silver grey when dry. It is found in semi-desert scrub and on limestone plateaus, often in cracks in cliffs and under boulders. Distribution: Madagascar, East Africa and the Arabian Peninsula (Miller et al., 1996).

\section{Anogramma leptophylla (L.) Link}

This is an unusual fern species, with a perennial gametophyte and annual sporophyte. The large gametophytes can lie dormant for up to two years until the conditions are right to produce fertile fronds (Ensoll, pers. comm.). It has a worldwide distribution range in temperate regions, and is most often found on damp, shady rocks and cliffs. 
Aleuritopteris scioana Chiov. Fraser-Jenk. \& Dulawat

This is a small green fern species which has white farinose powder on the underside of the fronds. It grows in shady crevices or limestone cliffs in East Africa, Arabia and India.

\section{Spore extraction from herbarium sheets}

A hand lens was used to check the condition of the mature fronds and for the presence of spores on each herbarium sheet. Preference for spore selection was given to those in small paper envelopes containing additional plant material, known as 'capsules', on the sheet (see Figs 1, $2 \& 3$ ). For specimens that did not have these capsules, pinnules were removed from fronds that were folded or overlapping other fronds so that damage to the herbarium specimen was kept to a minimum. Loose spores present on the paper were not collected, because these may have been contaminant spores from other specimens. Spores were transferred into miniature envelopes prior to sowing.

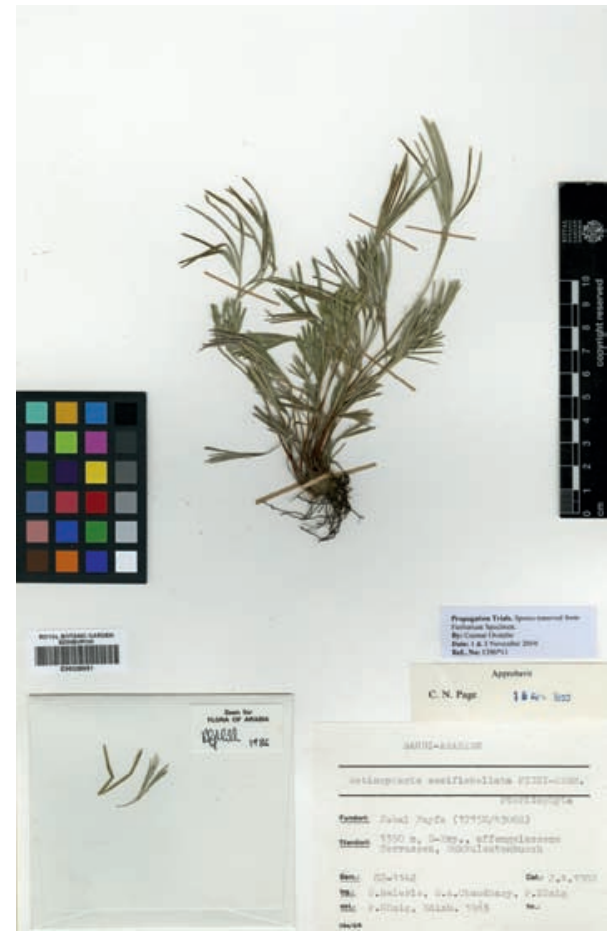

Fig. 1 Herbarium specimen of Actiniopteris semiflabellata. Spores were taken from the capsule in the lower left-hand corner of the sheet. Scan: Muhammad Ghazali.

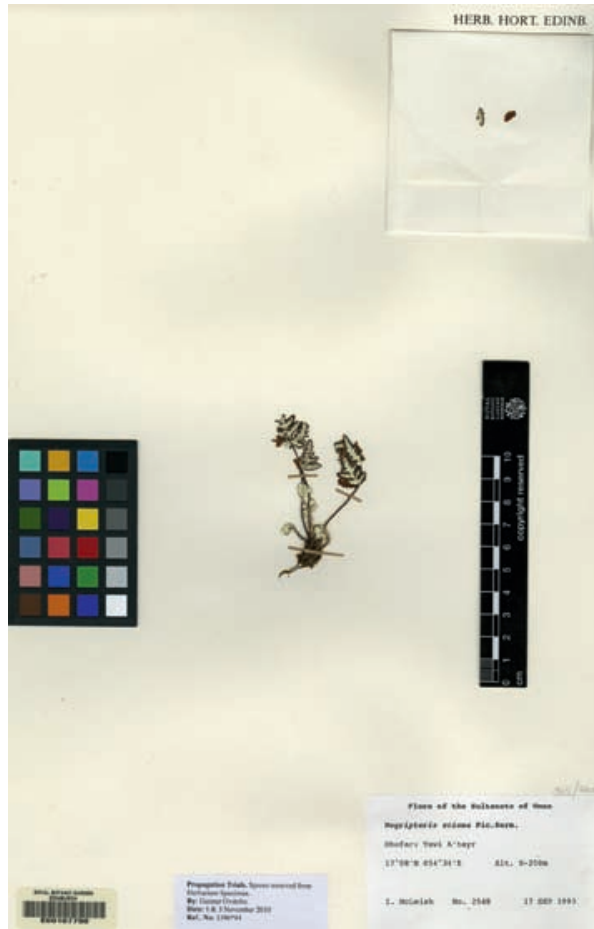

Fig. 2 Herbarium specimen of Aleuritopteris scioana. Spores were taken from material in the capsule in the top right-hand corner of the sheet. Scan: Muhammad Ghazali. 


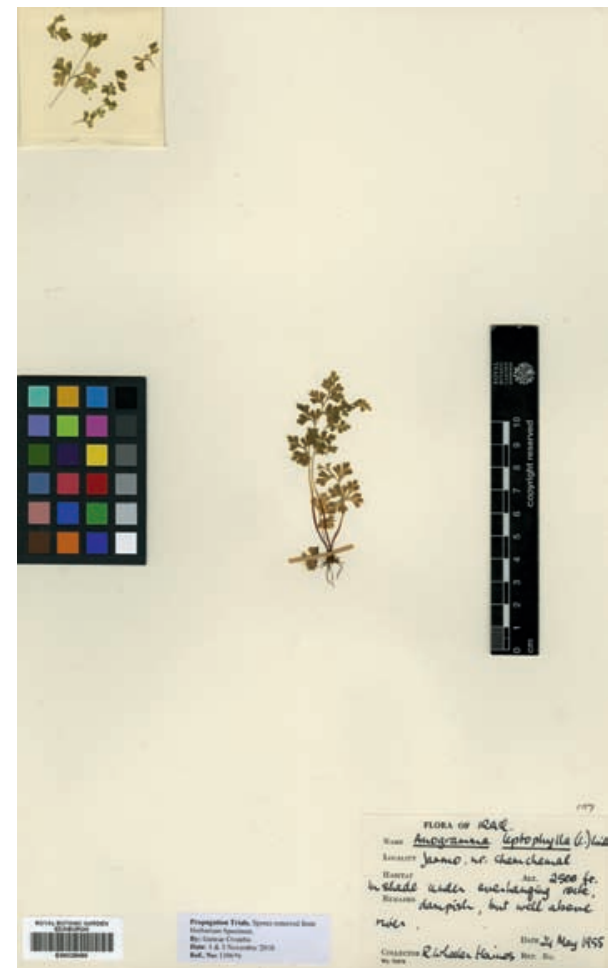

Fig. 3 Herbarium specimen of Anogramma Leptophylla. Spores were taken from material in the capsule in the top left-hand corner of the sheet. Scan: Muhammad Ghazali.

\section{Spore cleaning}

Spores were cleaned in the horticultural research propagation area. Special care was required to avoid cross-contamination. The worktops and tools were cleaned prior to use and spore handling was minimised. Only a single sample was cleaned at any one time, and the papers used for sowing spores were not reused. The miniature envelopes containing the fronds were agitated with the end of a pencil to shake the spores loose. The contents were poured onto a clean piece of paper and debris was removed.

\section{Compost and sowing}

For this germination study, spores were sown on compost rather than on sterile agar medium. Although the use of agar plates allows the emergence of rhizoids to be observed and germination percentage to be calculated, growing spores on soil is the preferable method for strong root growth and for the long-term cultivation of ferns. Preparation of spore compost and sterilisation was carried out using the protocol described in Ensoll \& Matthews (2004). The mix was prepared as follows: sieved fine bark was mixed with loam to make a free-draining mix which retained sufficient moisture. Clean $4 \mathrm{~cm}$ square pots were filled with the mix, leaving sufficient space for the gametophytes to grow. The containers and their contents were sterilised by pouring boiling water over them and waiting for the contents to flow through before repeating the procedure. Six pots were sterilised simultaneously. To avoid contamination and pest infection the pots were then enclosed in plastic bags.

\section{Sowing spores}

Prior to sowing, labels were prepared with the species name, barcode reference number and date of sowing. Cleaned spores were then dispersed thinly onto a piece of paper and inverted onto the surface of the sterilised compost. The paper was lightly tapped with the end of a pencil to dislodge the spores and the label inserted. The entire pot was then 
tightly enclosed with cling film to retain moisture. Exposure of the surface of the pot to the air was kept to a minimum to avoid contamination from other spores in the air. One pot per collection of spores from each herbarium specimen was sown. The pots were placed in a growing room $12 \mathrm{~cm}$ below a daylight bulb which was set for 13-hour days. The temperature was maintained at $21^{\circ} \mathrm{C}$.

\section{Scoring spore germination}

The pots were checked for spore germination at three-day intervals. After six weeks young prothallia were observed and additional moisture was given with a water sprayer set on a fine mist to dampen the compost and increase humidity. Cling film degenerates rapidly under moist conditions and was replaced every four weeks.

\section{RESULTS}

\section{Spore germination by specimen age}

The relative success of spore germination from recent herbarium specimens, when compared with older specimens, suggests that the age of the specimen, or a factor related to specimen age, has an effect on spore viability. No specimens collected prior to 1950 germinated, however the number of available samples was low so it would be unwise to draw firm conclusions from this. Some spores germinated from the more recently collected material from all three fern species tested here. For example, there was successful germination from the 1955, 1982 and 1990 specimens of Anogramma leptophylla, but not from the collection made in 1942. Generally, spore germination from recently collected herbarium material was lower than what could be expected had the spores been collected in the field for the purpose of sowing immediately on return to RBGE.

\section{Spore germination by species}

Actiniopteris semiflabellata: Four out of eight herbarium specimens had viable spores. Gametophytes were observed 14 weeks after spores were sown (see Fig. 4). A large number of spores were present on the herbarium sheets which may have contributed to the high level of germination. The reflexed margins, which curl back over the sori, may act to retain spores on the dried fronds.

Anogramma leptophylla: Three out of the four specimens tested had viable spores. Fifteen weeks after sowing there was no sign of sporophytes, and verification of the species was based on the character of the gametophytes alone. The gametophytes were larger in size and had a thicker and more leathery texture than the other fern gametophytes in this experiment (see Fig. 5). A large number of spores were identified both on 


\begin{tabular}{|c|c|c|c|}
\hline Species & $\begin{array}{l}\text { Collection } \\
\text { date }\end{array}$ & $\begin{array}{c}\text { Collection details } \\
\text { Country: Region. Collector }\end{array}$ & $\begin{array}{c}\text { Specimen } \\
\text { identification } \\
\text { barcode }\end{array}$ \\
\hline \multirow[t]{8}{*}{ Actiniopteris semiflabellata } & 1 Jul 1880 & YEMEN: Soqotra. Balfour & E00239740 \\
\hline & 1 Jul 1897 & YEMEN: Soqotra. Bent & E00328707 \\
\hline & 14 Sep 1978 & YEMEN: Taiz. Miller & E00328650 \\
\hline & 2 Apr 1982 & SAUDI ARABIA: Jabal Fayfa. König & E00328651* \\
\hline & 17 Nov 1982 & YEMEN: Wadi labdah. King & E00328652* \\
\hline & 23 Sep 1984 & OMAN: Dhofar. Miller & E00328686* \\
\hline & 19 Feb 1989 & YEMEN: Hadiboh. Miller & E00239741 \\
\hline & 2 Sep 1993 & OMAN: Dhofar. McLeish & E00128563 \\
\hline \multirow[t]{4}{*}{ Anogramma leptophylla } & 9 Apr 1942 & ISRAEL (Palestine). Davis & E00328689 \\
\hline & 24 May 1955 & IRAQ: Jarmo. Haines & E00328690* \\
\hline & 13 Feb 1982 & SAUDI ARABIA: Kharar. Collenette & E00328688* \\
\hline & 25 Apr 1990 & $\begin{array}{l}\text { SAUDI ARABIA: Jalal Ibrahim. } \\
\text { Collenette }\end{array}$ & E00328687* \\
\hline \multirow[t]{5}{*}{ Aleuritopteris scioana } & 17 Sep 1978 & YEMEN: Beni Miftah. Wood & E00328670 \\
\hline & 21 Sep 1979 & OMAN: Dhofar. Miller & E00328671 \\
\hline & 5 Oct 1979 & OMAN: Dhofar. Miller & E00328668 \\
\hline & 12 Oct 1979 & OMAN: Dhofar. Miller & E00328669 \\
\hline & 17 Sep 1993 & OMAN: Dhofar. McLeish & E00107750* \\
\hline
\end{tabular}

Table 1 The specimens marked with an asterisk contain viable spores, from which young plants were propagated and accessed to the RBGE Living Collection on 14 April 2011.

the herbarium sheet and in the capsule. The spores on the fronds are not protected with a frond margin and many were loose on the herbarium sheet.

Aleuritopteris scioana: The specimen of this species had the smallest amount of plant material on the herbarium sheet, and only one herbarium specimen yielded viable spores. Instead of the usual round or heart-shaped gametophytes these were moss-like in form. Twenty weeks after sowing they produced sporophytes (see Fig. 6).

\section{Weedy contaminants}

A number of weedy contaminant plant species grew in the trial pots. These are most likely to have come from spores and seeds present in the herbarium or the horticultural research area. Contaminant species included the fern genera Christella, Pellaea and Pteris, all of which are present in the Arabian Peninsula, but are also common weeds in horticulture. 


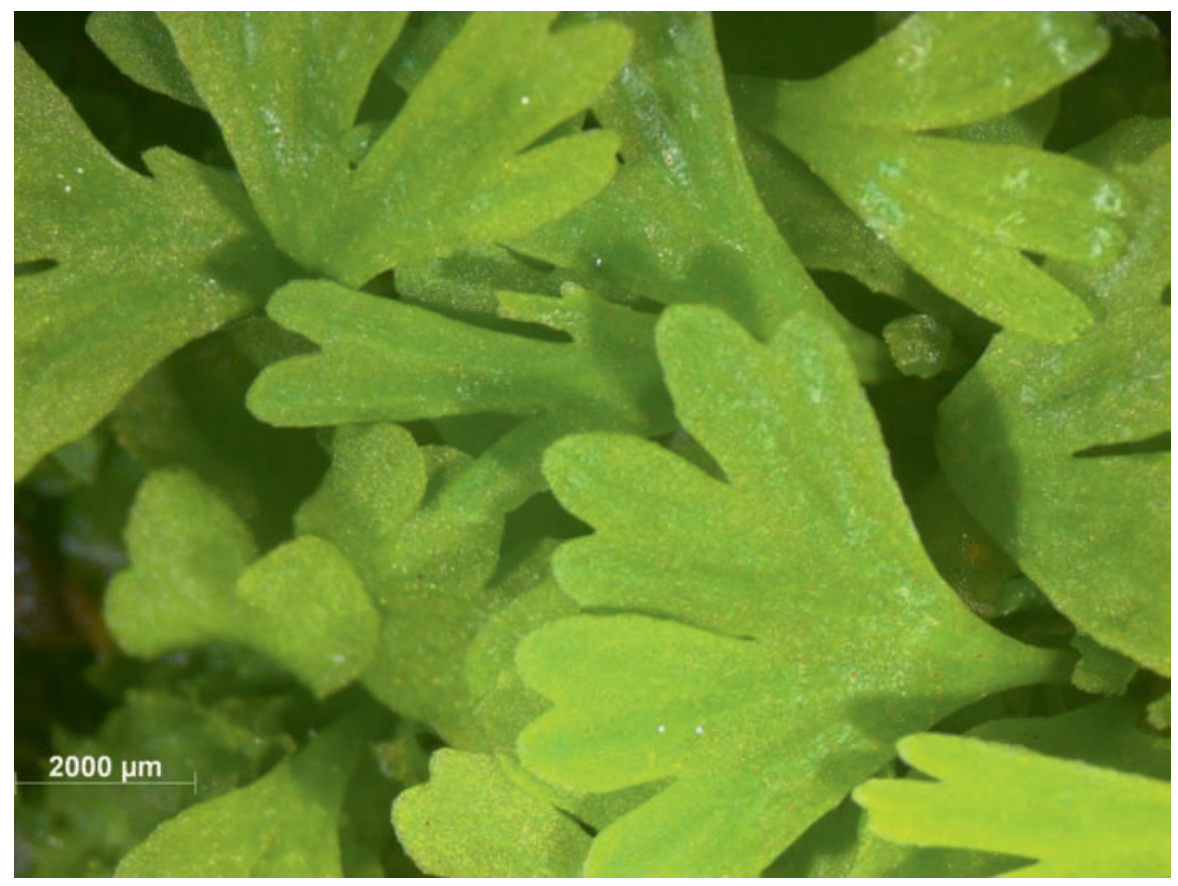

Fig. 4 Actiniopteris semiflabellata sporophytes 14 weeks after spores were sown. Photo: Gunnar Øvstebø.

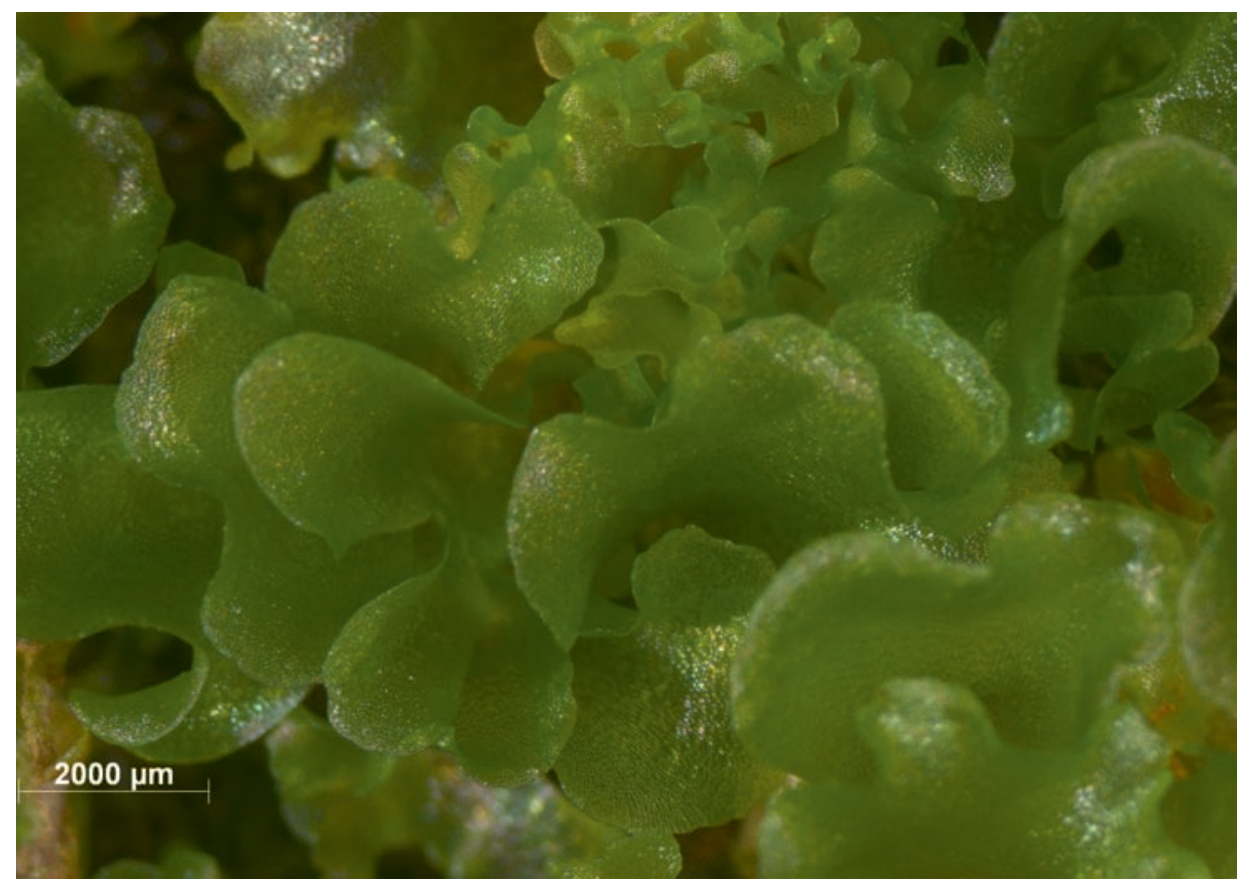

Fig. 5 Anogramma leptophylla gametophytes 12 weeks after spores were sown. Photo: Gunnar Øvstebø. 


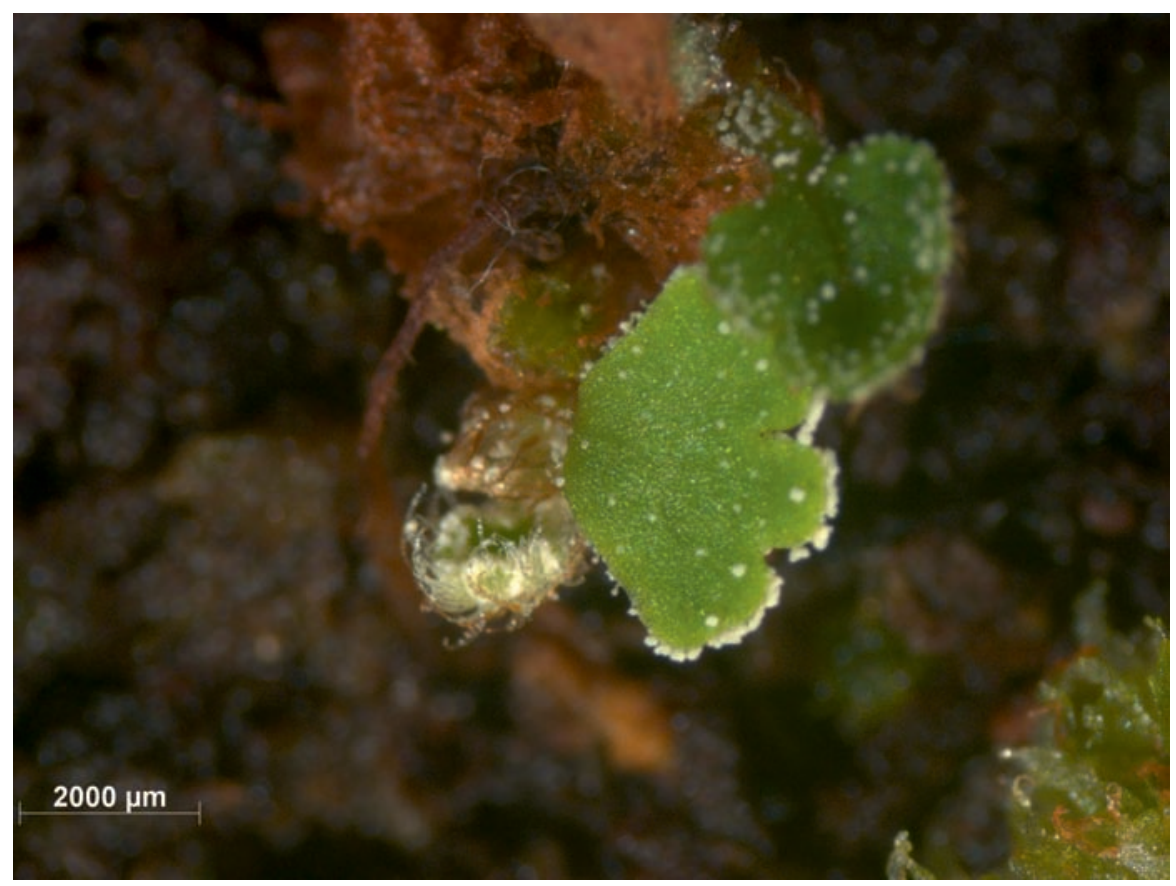

Fig. 6 Aleuritopteris scioana sporophytes 20 weeks after spores were sown. Photo: Gunnar Øvstebø.

\section{DISCUSSION}

Living plants germinated from herbarium collections may play a significant role in enhancing living plant collections (Rae, 2006) and increasing the legacy of past collection trips. This is particularly useful for species that have become extinct or rare in the wild due to habitat disturbance and climate change (Bowles et al., 1993). The ferns grown in this study will be planted in the Arid Lands display house at RBGE and will be a valuable contribution to the Living Collection. As a result of this study one accession of Actiniopteris semiflabellata of unknown provenance has been de-accessed and replaced with four new accessions of known wild-origin material from herbarium collections (see Fig. 7). The accession of Aleuritopteris scioana is the first to be grown at RBGE (see Fig. 8). The gametophytes derived from herbarium material collected in 1955 in Iraq of Anogramma leptophylla will be transplanted to a damp site sheltered by a rock in the Arid Lands display house. These additions to the Living Collection will be particularly valuable as an educational resource for illustrating the range of adaptations that plants have to harsh environments. The theme of arid ferns on display has already had positive feedback and interest from visitors and students.

There are two benefits to sourcing wild-origin plants from herbarium collections and these are reasons why the herbarium should be cautiously considered as a potential source of living spores. First, it provides an opportunity to retrieve genotypes of limited 


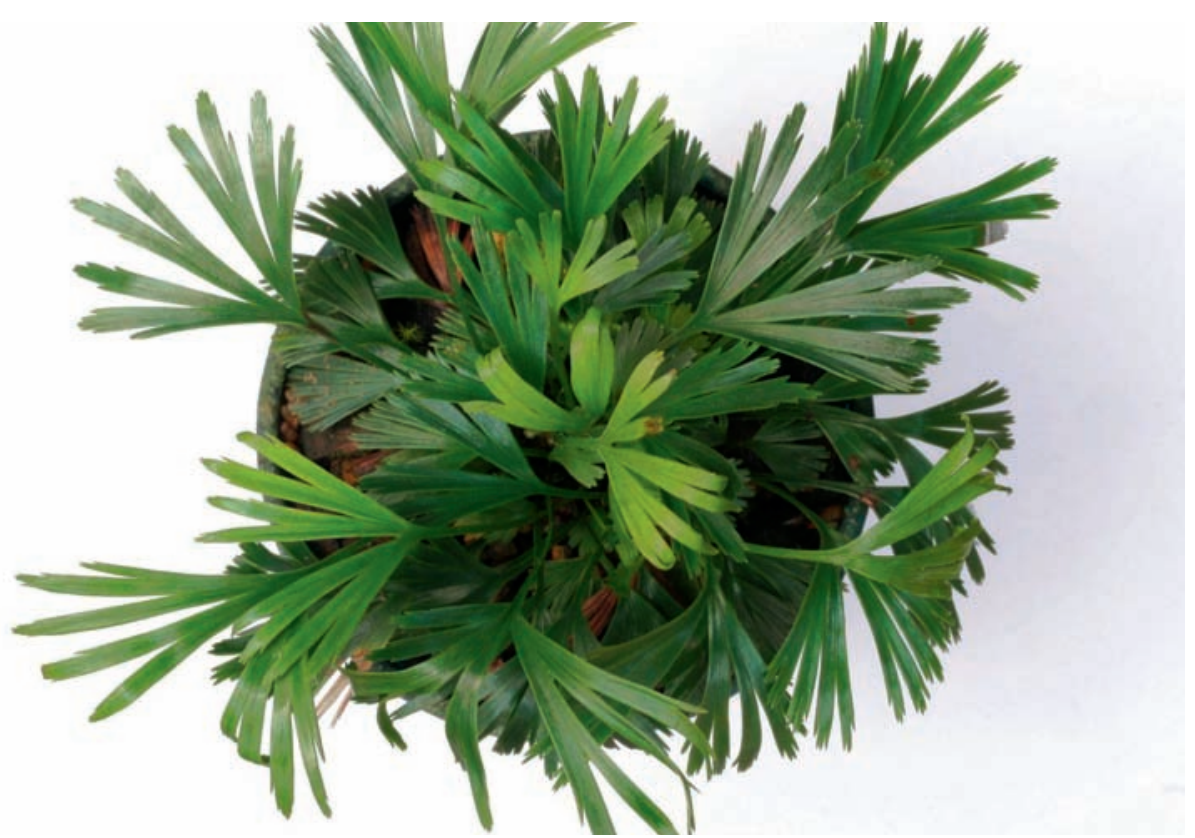

Fig. 7 Young sporophyte of Actiniopteris semiflabellata. It germinated 28 weeks after spores were sown 30 years after collection of the specimen. Photo: Sadie Barber.

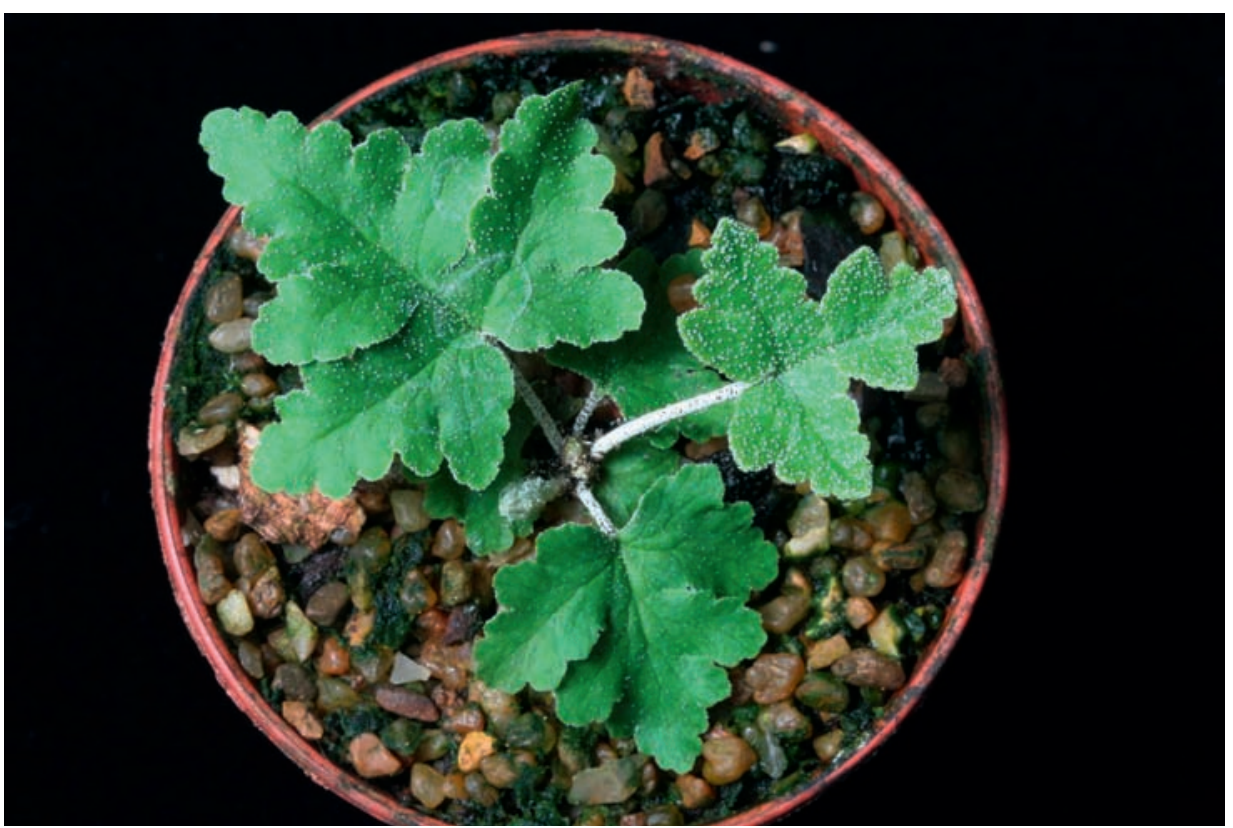

Fig. 8 Young sporophyte of Aleuritopteris scioana 28 weeks after spores were sown. Photo: Sadie Barber. 
availability (discussed above). The second is that it is a more cost-effective way to introduce plants than carrying out new fieldwork. However, the introduction of material from herbarium collections presents a number of legal and moral challenges which must be considered prior to embarking on such work. Most importantly, cultivation of material from herbarium specimens must follow the terms of the Convention on Biological Diversity (CBD) (Williams, 2003). All the material used in this study was collected prior to December 1993, and therefore prior to the establishment of the CBD, and thus is not subject to its regulations. However, future studies using herbarium collections must ensure that the correct permissions have been granted to collect this material and assurances made that there will be no financial gain from cultivating the plants.

The optimum conditions for the storage of spores is likely to be in refrigerated spore banks and many studies have investigated the lifespan of spores in these conditions (Dyer et al., 1979). In this study, we have shown that collections stored in the herbarium may provide an additional source of living germplasm. We suggest that recent herbarium collections should be the priority for germination trials. Future projects should make a more critical assessment of the viability of spores, rather than the presence or absence of germinating spores, so that more detailed recommendations can be made about the conditions in which spores will survive. Also the effect of drying techniques, temperature and chemical treatments should be taken into consideration (Windham et al., 1986).

\section{CONCLUSION}

Herbarium curators go to great lengths to kill all living organisms in herbarium collections, whilst maintaining the structure and usability of the specimens. Yet this study shows that the germination of spores derived from historic herbarium material may be a method to increase the range of species cultivated in living collections. This may be extended in the future to the cultivation of fern species which are rare or extinct in the wild.

\section{ACKNOWLEDGEMENTS}

We would like to thank Tony Miller for encouraging us to start this project, Suzanne Cubey and Elspeth Haston for assistance in the RBGE Herbarium and data capture, and Andrew Ensoll for advice on fern cultivation. Stuart Lindsay's and Mary Gibby's advice on the manuscript was invaluable. Finally, thank you to David Rae and the horticulture staff at RBGE for their support throughout the project.

\section{REFERENCES}

BOWLES, M.L., BETZ, R.F. \& DEMAURO, M.M. (1993). Propagation of rare plants from historic seed collections: Implications for species restoration and herbarium management. Restoration Ecology 1, 101-106. 
DYER, A.F. (ed.) (1979). The Experimental Biology of Ferns. London: Academic Press.

ENSOLL, A. \& MATTHEWS, K. (2004) Cultivation of Thyrsopteris elegans. Sibbaldia 2, 27-32.

FERNANDEZ, H. (ed.) (2010). Working with Ferns: Issues and Applications. London: SpringerScience+Business Media.

JOHNSON, M.D. (1985). New records for longevity of Marsilea sporocarps. American Fern Journal 75, 30-31.

MEHLTRETER, K., WALKER, L.R. \& SHARPE, J.M. (eds) (2010). Fern Ecology. Cambridge: Cambridge University Press.

MILLER, A.G. \& COPE, T.A. (1996). Flora of the Arabian Peninsula and Socotra. Vol. 1. Edinburgh: Edinburgh University Press.

PRAY, T.R. (1968). The gametophytes of Pellaea section Pellaea: dark-stiped series. Phytomorphology 18, 113.

RAE, D. (ed.) (2006). Collection Policy for the Living Collection. Edinburgh: Royal Botanic Garden Edinburgh.

RANKER, T.A. \& HAUFLER, C.H. (eds) (2008). Biology and Evolution of Ferns and Lycophytes. Cambridge: Cambridge University Press.

ROYAL BOTANIC GARDEN EDINBURGH (2010). Herbarium Catalogue. Available at: www. rbge.org.uk/databases (accessed May 2011).

WILLIAMS, C. (ed.) (2003). The CBD for Botanists: An Introduction to the Convention on Biological Diversity for People Working with Botanical Collections. Kew: Board of Trustees, Royal Botanic Gardens, Kew.

WINDHAM, M.D. \& HAUFLER, C.H. (1986). Biosystematic uses of fern gametophytes derived from herbarium specimens. American Fern Journal 76, 114-128.

WINDHAM, M.D., WOLF, P.G. \& RANKER, T.A. (1986). Factors affecting prolonged spore viability in herbarium collections of three species of Pellaea. American Fern Journal 76, 141-148. 
RB27908.indb 54 